\title{
Systemic effects of inhalational methyl bromide poisoning: a study of nine cases occupationally exposed due to inadvertent spread during fumigation
}

\author{
W N M Hustinx, R T H van de Laar, A C van Huffelen, J C Verwey, J Meulenbelt, \\ T J F Savelkoul
}

\begin{abstract}
Systemic methyl bromide $\left(\mathrm{CH}_{3} \mathrm{Br}\right)$ poisoning with signs and symptoms of varying severity developed in nine greenhouse workers after acute inhalational exposure on two consecutive days. Measurements of $\mathrm{CH}_{3} \mathrm{Br}$, carried out at the site within hours after the accident, suggest that exposure on the second day may have been in excess of $200 \mathrm{ppm}\left(800 \mathrm{mg} / \mathrm{m}^{3}\right) \mathrm{CH}_{3} \mathrm{Br}$. All workers were admitted for observation. Seven of them were discharged after an uneventful overnight observation and residual symptoms, if any, subsided within three weeks of the accident. Two patients needed intensive care for several weeks because of severe reactive myoclonus and tonic-clonic generalised convulsions. These conditions were unresponsive to repeated doses of diazepam, clonazepam, and diphenylhydantoin but could be suppressed effectively by induction of a thiopental coma that had to be continued for three weeks. In some of the patients prior subchronic exposure to $\mathrm{CH}_{3} \mathrm{Br}$, as shown by their occupational histories and high serum bromide $\left(\mathrm{Br}^{-}\right)$concentrations, is likely to have been a factor contributing to the severity of their symptoms. A direct association between serum $\mathrm{Br}^{-}$concentrations and the severity of neurological symptoms, however, seemed to
\end{abstract}

\footnotetext{
Department of Intensive Care and Clinical Toxicology

W N M Hustinx, J Meulenbelt, T J F Savelkoul

Department of Clinical Neurophysiology

A C van Huffelen

Department of Neurology, Utrecht State University

Hospital

J C Verwey

National Poison Control Centre, National Institute of Public Health and Environmental Protection

W $N$ M Hustinx, $R$ T $H$ van de Laar, J Meulenbelt, T J F Savelkoul
}

be absent. An on site investigation into the circumstances leading to the accident showed the presence of an empty and out of use drainage system that covered both sections of the greenhouse. This was probably the most important factor contributing to the rapid and inadvertent spread of $\mathrm{CH}_{3} \mathrm{Br}$.

\section{(British Journal of Industrial Medicine 1993;50:155-159)}

In the past methyl bromide $\left(\mathrm{CH}_{3} \mathrm{Br}\right)$ was mainly used as a fire extinguisher. In 1932 it was introduced as an insecticide. Nowadays the compound is primarily used as a fumigant for the control of nematodes, fungi, and weeds in greenhouses, warehouses, and mills. It is a colourless, non-inflammable, and highly volatile substance and exists in the gaseous phase at normal pressures and temperatures. It has a density of more than three times that of air, which may explain its easy penetration in soil. Furthermore, it has poor warning properties because it is odourless at concentrations of up to 100 times the Dutch maximum allowable concentration (MAC) of $5 \mathrm{ppm} .{ }^{1}$ This may explain why $\mathrm{CH}_{3} \mathrm{Br}$ has so often caused serious and sometimes fatal poisoning. ${ }^{2-4}$ Alexeeff and Kilgore have extensively summarised and reviewed the reported poisoning incidents from $\mathrm{CH}_{3} \mathrm{Br} .{ }^{5}$ They are not infrequently fatal. Legislative measures have considerably restricted the use of the compound in The Netherlands since 1981 . The present report of occupational poisoning with $\mathrm{CH}_{3} \mathrm{Br}$ underscores the need for continuous monitoring in and around fumigation sites as an integral part of good fumigation practice. It also shows the difficulties that may be encountered in the clinical management of the neurological manifestations of serious systemic $\mathrm{CH}_{3} \mathrm{Br}$ poisoning. Generalised seizures after poisoning with $\mathrm{CH}_{3} \mathrm{Br}$ may be resistant to treatment with drugs like diazepam, clonazepam, and diphenylhydantoin. We describe treatment with thiopental as an effective alternative. 


\section{Materials and methods}

The accident came to the attention of the National Poison Control Centre (NVIC) through requests for information about $\mathrm{CH}_{3} \mathrm{Br}$ poisoning by general practitioners and physicians in neighbouring hospitals where two greenhouse workers, with serious neurological signs of $\mathrm{CH}_{3} \mathrm{Br}$ poisoning, had been admitted. From interviews with their relatives and the greenhouse owner it became clear that another seven people had probably been exposed to $\mathrm{CH}_{3} \mathrm{Br}$ as well. They were all traced within hours and admitted to the intensive care and clinical toxicology department of Utrecht State University Hospital for clinical observation, the department being an integrated unit with the NVIC. The two serious cases were also transferred to that same intensive care unit. All patients were examined by an internist and a neurologist. Further investigations included (1) blood sampling for routine haematology, biochemical tests, and measurement of serum $\mathrm{Br}^{-}$and blood $\mathrm{CH}_{3} \mathrm{Br}$ concentrations. This was repeated six and 12 hours after admission and again six and 19 days later; (2) urinalysis, including a semiquantitative check on the presence of glucose, protein and traces of blood; (3) chest radiography; (4) blood gas analysis; (5) electrocardiography (ECG); (6) daily monitoring of seizure activity with 20-channel electroencephalography together with ECG and movement recording, when indicated by abnormal findings on neurological examination. Measurement of blood $\mathrm{CH}_{3} \mathrm{Br}$ concentrations was performed by gas chromatographic analysis of air samples from head space tubes (detection limit $0.005 \mu \mathrm{g} / \mathrm{ml}$ ) and serum bromide $\left(\mathrm{Br}^{-}\right)$measurements by induction coupled plasma mass spectrometry (detection limit $3 \mu \mathrm{g} / \mathrm{l}$ ) (Laboratory for Inorganic Chemistry, National Institute of Public Health and Environmental Protection). Data regarding the circumstances of the accident were collected by the NVIC occupational hygienist through interviews with patients, the greenhouse owner, and employees of the firm that contracted the fumigation job. He also visited the site of the accident. Repeated $\mathrm{CH}_{3} \mathrm{Br}$ measurements were carried out for 19 days after the accident with a Dräger gas detector (tubes $3 / a$ and $5 / a$ with detection limits of $3 \mathrm{ppm}$ and $5 \mathrm{ppm}$ respectively). Measurements were done in ambient air at 10-100 $\mathrm{cm}$ above ground level. Whenever it was considered relevant in describing the sequelae of the accident, patients are identified in the text by numbers in parentheses.

\section{Results}

\section{CIRCUMSTANCES OF THE ACCIDENT}

The accident occurred in a greenhouse consisting of two sections with a surface area of almost $8500 \mathrm{~m}^{2}$ each, separated by a glass partition wall. A door in this wall was sealed with weather stripping. The partition wall had its foundations $30-35 \mathrm{~cm}$ below ground level. At a height of around $2 \mathrm{~m}$ above ground level several heating pipes passed the partition through poorly sealed openings. The water drainage system, running at a depth of $100 \mathrm{~cm}$ and covering both sections, had been closed before fumigation started. After the accident, an empty and out of use set of drainage pipes was found at a depth of $120 \mathrm{~cm}$, $80 \mathrm{~cm}$ above ground water level. These pipes also crossed the partition and covered the entire length of the greenhouse. Both sections were heated at the time of the accident. The recorded temperatures ranged from $15^{\circ} \mathrm{C}$ in the fumigated section to $17^{\circ} \mathrm{C}$ near the glass partition and $21^{\circ} \mathrm{C}$ at the far end of the nonfumigated section. Soil temperature was $<21^{\circ} \mathrm{C}$ in both sections. Of the non-fumigated section only the part nearest to the partition wall was slightly ventilated. The soil consisted of clay and was prepared for fumigation by rooting to $60 \mathrm{~cm}$ below ground level. The sections were fumigated separately with an interval of three weeks. The section where the exposure occurred had been fumigated three weeks earlier. Fumigation was carried out from a pressurised vapouriser, stationed outside the greenhouse, by application of hot vapour through perforated tubing under gas tight plastic sheeting. The sheeting was removed 10 days after fumigation. The dose used $\left(200 \mathrm{~g} / \mathrm{m}^{2}\right)$ was five times the legally allowed dose. During fumigation, a $\mathrm{CH}_{3} \mathrm{Br}$ concentration of $25 \mathrm{ppm}\left(100 \mathrm{mg} / \mathrm{m}^{3}\right)$ was measured near the glass partition in the non-fumigated section. Away from the partition wall, concentrations rapidly declined to below the detection limit. An employee working near the partition was advised to keep away from it. Unfortunately no repeat measurements were done until after the accident. Five hours after all the workers were forced to leave the greenhouse on the second day, $\mathrm{CH}_{3} \mathrm{Br}$ concentrations ranged from 200 ppm near the partition-wall to $150 \mathrm{ppm}$ at the far end of the non-fumigated section. No $\mathrm{CH}_{3} \mathrm{Br}$ was detectable at the outside perimeter of the greenhouse. Sixteen days after the accident the $\mathrm{CH}_{3} \mathrm{Br}$ concentration in the fumigated section had fallen to below the Dutch MAC of $5 \mathrm{ppm}$ and it took 20 days for $\mathrm{CH}_{3} \mathrm{Br}$ to become undetectable. In the non-fumigated section $\mathrm{CH}_{3} \mathrm{Br}$ concentrations had dropped to MAC and zero after five and 15 days respectively.

\section{PATIENTS}

The accident involved nine greenhouse workers (two women, seven men; age 21-40 years). Three weeks before the accident five of them $(2,3,5,8,9)$, including the two patients ( 8 and 9 ) with serious neurological signs of poisoning, had been working in the section of the greenhouse later to be fumigated, while fumigation was in process in the other section. Already at that time, two workers ( 3 and 6 ) had experienced symptoms (nausea, vomiting, and dizzi- 
ness) that might retrospectively be attributable to $\mathrm{CH}_{3} \mathrm{Br}$ poisoning. Another worker (9) had been involved in a car crash two weeks before the poisoning accident. The man had a complete amnesia for the car accident despite no evidence of skull or brain damage. His relatives reported a striking absent mindedness that had become apparent already before the accident. Apart from these data, the medical histories of all workers were unremarkable. All patients had been working in the non-fumigated section of the greenhouse on the day before the accident for an average of six hours (range four to eight hours). Most of them had already experienced some degree of nausea and headache in the course of that day. This caused two of them (1 and 6) to stay at home the next day. Two hours after the remaining seven workers had resumed their work on the next day, all except one (7) (who only reported a slight burning sensation in the throat) quite suddenly and almost simultaneously experienced extreme nausea, repeated vomiting, and dizziness. This forced all of them to leave the greenhouse and go home. Two hours later while at home two workers ( 8 and 9 ), developed twitching of all limbs followed by generalised seizures. On admission these two patients showed a uniform picture characterised by coma (Glasgow coma scale $\mathrm{E}_{1} \mathbf{M}_{3} \mathrm{~V}_{1}$ ) and myoclonic contractions of all limbs but predominantly of the arms that could be provoked or aggravated by touching the body. This myoclonic activity precluded a correct assessment of muscle power and sensory functions. In addition generalised seizures occurred at regular intervals. Apart from absent peristalsis physical examination showed no other abnormalities at that time. Repeated intravenous doses of clonazepam, diazepam, and a diphenylhydantoin loading dose did not arrest the seizures. A thiopental coma was then induced and mechanical ventilation started. Electroencephalograms in conjunction with measurements of serum thiopental concentrations were performed at regular intervals to evaluate the efficacy of the thiopental dosing regimen. Recordings with a suppression-burst pattern showing suppression-periods of 5-10 seconds were considered to represent adequate suppression of convulsive activity. This effect was achieved immediately and could be maintained by blood thiopental concentrations ranging from 40 to $70 \mu \mathrm{g} / 1$. Both patients were receiving diphenylhydantoin as comedication. Three days after admission their chest $x$ ray films showed unilateral infiltrative changes with some pleural effusion that gradually disappeared within the next 10-14 days. Persisting intermittent fever and varying degrees of leucocytosis with or without left shift existed in both of them for more than three weeks despite several courses of broad spectrum antimicrobial treatment. Repeated cultures of blood, sputum, and urine remained negative or grew microorganisms considered to be contaminants. For some time both patients had to be ventilated with $0.4-0.5$ fractional inspired oxygen but application of positive end expiratory pressure was never considered necessary. It took three weeks before thiopental administration could be withdrawn after electroencephalograms had shown epileptiform patterns to return only sporadically in its absence. More than two months after admission one patient could be transferred to a physical rehabilitation centre, still suffering from debilitating proximal action and distal intention myoclonus unresponsive to experimental treatment with 5-hydroxytryptophan. Muscle power, sensory function, and reflexes were all normal. Four months after the accident the proximal action myoclonus had completely disappeared, although the distal intention myoclonus had remained unchanged. The second serious case could be transferred to a physical rehabilitation centre three months after admission. As well as a similar distal action myoclonus, he showed a slight distal muscular weakness of the legs and a painful plantar dysaesthesia, and tendon reflexes were brisk except for a diminished ankle jerk reflex. These signs of axonal neuropathy improved only slightly over the six months after the accident. Intellectually both patients, who regained consciousness soon after withdrawal of thiopental rapidly improved to near normal. In both of them a similar rise in ALAT-ASAT, and LDH activities occurred that started three days after admission with peak values of roughly 130,170 , and $520 \mathrm{U} / 1$ respectively on the sixth day of admission and a return to normal values soon afterwards. High initial CK activities returned to normal soon after adequate suppression of seizure activity was established.

Signs and symptoms in the other seven patients were remarkably uniform and included headache, nausea, and a sensation described as "floating." One patient (3) complained of unsteady gait. Neurological examination confirmed mild ataxia (that persisted for a fortnight) whereas in another man (2) a slurred speech had developed that disappeared 16 hours later. Physical examination was otherwise unremarkable in these patients, who were all discharged after an uneventful overnight observation. Routine laboratory tests, chest $x$ ray films, ECG, and urinalysis showed no gross abnormalities except for raised serum chloride concentrations in some patients. The likely reason for this is discussed later. Most of the patients were seen again for a check up and blood sampling (to monitor serum $\mathrm{Br}^{-}$concentrations) on days 6 and 19 after the accident. By then all residual complaints (mostly mild headache, nausea, and loss of appetite) had disappeared. Electroencephalography was performed in four patients. They proved normal in two patients who had developed slurring of speech (2) and mild ataxia (3). In the two serious cases the recordings showed a remarkable 
Table Concentrations of methyl bromide in blood and of bromide ion in serum of nine patients exposed to methyl bromide

\begin{tabular}{llrrrrr}
\hline \multirow{2}{*}{$\begin{array}{ll}\text { Patient } \\
n o\end{array}$} & $\mathrm{CH}_{3} \mathrm{Br}$ & \multicolumn{2}{l}{$\mathrm{Br}^{-}(\mathrm{mg} / \mathrm{l})$} & & & \\
\cline { 3 - 7 } & $T_{24 h}$ & $T_{12 h}$ & $T_{18 h}$ & $T_{24 h}$ & $T_{6 d}$ & $T_{19 d}$ \\
\hline 1 & ND & 54 & 56 & 51 & 42 & 22 \\
2 & ND & 273 & - & 269 & 227 & 119 \\
3 & ND & 72 & 69 & 69 & 55 & 30 \\
4 & ND & 59 & 56 & 57 & 44 & 22 \\
5 & ND & 186 & 185 & 188 & 127 & - \\
6 & ND & - & 75 & 74 & 48 & 14 \\
7 & ND & 51 & 56 & 55 & 36 & - \\
8 & ND & $363^{\star}$ & - & - & 189 & 66 \\
9 & ND & $267^{\star}$ & 238 & 225 & 25 & 5 \\
\hline
\end{tabular}

$\mathbf{T}=$ Time elapsed, expressed as hours (h) or days (d) after exposure; ND = not detectable (detection limit $0.005 \mu \mathrm{g} / \mathrm{ml}$ ); *bromide concentrations in serum of patients (8 and 9) as measured in the referring hospital at $T_{4 h}$ were 460 and $320 \mathrm{mg} / 1$ respectively; $\mathrm{Br}^{-}=$bromide ion (detection limit $3 \mu \mathrm{g} / \mathrm{l}$; normal value for the Dutch population 3.5-5.5 mg// ${ }^{112}$ ).

pattern. There were runs of very sharp spikes of short duration followed by a short wave. Myoclonic jerks coincided with these polyspike and wave complexes. These spikes were of such a short duration that they resembled muscle artefacts but apparently were not of such origin because they persisted after the administration of muscle relaxants.

\section{ANALYTICAL TOXICOLOGY}

Table 1 presents results of blood $\mathrm{CH}_{3} \mathrm{Br}$ and serum $\mathrm{Br}^{-}$measurements. No $\mathrm{CH}_{3} \mathrm{Br}$ was detectable in any of the samples (detection limit 0.005 $\mu \mathrm{g} / \mathrm{l}$ ). Serum $\mathrm{Br}^{-}$ concentrations (detection limit $3 \mu \mathrm{g} / \mathrm{l}$ ) were considerably increased in all patients, most notably in four $(2,5,8$, and 9$)$ of five patients whose histories suggested the possibility of repeated subchronic exposure to $\mathrm{CH}_{3} \mathrm{Br}$ in the weeks preceding the accident. Among them were the two transferred serious cases ( 8 and 9 ) and the patient with transient slurring of his speech (2).

\section{Discussion}

A dry and out of use set of drainage pipes, crossing both greenhouse sections over their entire length, was identified as the most likely major cause of considerable and rapid spread of $\mathrm{CH}_{3} \mathrm{Br}$ to the nonfumigated section. Other contributing factors were the dose of $\mathrm{CH}_{3} \mathrm{Br}$ used for fumigation (five times the accepted dose of $40 \mathrm{~g} / \mathrm{m}^{2}$ ), the higher temperature in the non-fumigated section, and the fact that the glass partition wall separating the sections had its foundation at only $30-35 \mathrm{~cm}$ below ground level, and showed some poorly sealed openings. This may explain why $\mathrm{CH}_{3} \mathrm{Br}$ concentrations close to it were higher compared with the more remote parts of the section. In as much as $\mathrm{CH}_{3} \mathrm{Br}$ concentrations, measured five hours after the accident (200 ppm), can be taken to reflect the actual $\mathrm{CH}_{3} \mathrm{Br}$ concentrations at the time of the accident, they clearly illustrate the poor warning properties of $\mathrm{CH}_{3} \mathrm{Br}$ at concentrations below $500 \mathrm{ppm}$ where $\mathrm{CH}_{3} \mathrm{Br}$ reportedly gets a faintly acrid smell. On the day of the actual fumigation, a single $\mathrm{CH}_{3} \mathrm{Br}$ measurement near the partition wall in the non-fumigated section indicated $\mathrm{a} \mathrm{CH}_{3} \mathrm{Br}$ concentration of $25 \mathrm{ppm}$ or five times the MAC value. Despite this, no ongoing monitoring was carried out on that same day or the next day. This accident therefore shows the need for continuous monitoring and supervision in and around the fumigated site as an integral part of good practice in fumigationactivities of this kind, as has already been suggested by various authors. ${ }^{178}$

Blood sampling (with the specific purpose of detection of $\mathrm{CH}_{3} \mathrm{Br}$ ) was not carried out until 24 hours after the accident. A likely explanation for the absence of detectable $\mathrm{CH}_{3} \mathrm{Br}$ in those samples is a short half life for $\mathrm{CH}_{3} \mathrm{Br}$ in humans. Experimental studies in rats $^{910}$ support this explanation. The biological half life of the bromide ion is $10-12$ days. ${ }^{112}$ Normal values of serum $\mathrm{Br}^{-}$concentrations in the Dutch population are between 3.5 and 5.5 $\mathrm{mg} / \mathrm{l} .{ }^{13}$ Its distribution and behaviour in the human body is like that of the chloride ion. In the everyday laboratory practice of most hospitals the measured chloride ion concentrations actually represent the total concentration of halogens. ${ }^{13}$ This may explain the high chloride concentrations in patients with very high $\mathrm{Br}^{-}$concentrations $\left(2,5,8\right.$, and 9). Serum $\mathrm{Br}^{-}$ concentrations are considered by some authors ${ }^{14} 15$ (but not all $^{77}$ ) to correlate poorly with clinical symptoms and outcome. The considerable difference in signs and symptoms between patients 2 , transient slurring of speech; 5 , transient burning sensation in the throat; and 8 and 9, reactive myoclonus and generalised convulsions, who had comparably high serum $\mathrm{Br}^{-}$concentrations illustrate this.

Cases of fatal $\mathrm{CH}_{3} \mathrm{Br}$ poisoning have reportedly occurred in association with serum $\mathrm{Br}^{-}$concentrations of only $30 \mathrm{mg} / \mathrm{l}$ whereas concentrations of more than $200 \mathrm{mg} / 1$ were found in professional fumigators without any accompanying symptoms. ${ }^{16}$ Those data are in line with the commonly held view that the strong alkylating (methylating) properties of intact $\mathrm{CH}_{3} \mathrm{Br}$ and not the $\mathrm{Br}^{-}$residues are responsible for the toxicity of that compound. In some of our patients $(2,5,8$ and 9) intermittent (sub)chronic occupational exposure is likely to have occurred in the weeks preceding the accident although preaccident values of serum $\mathrm{Br}^{-}$concentrations would have been needed to validate this hypothesis. Acute exposure superimposed on subchronic or intermittent acute and low level exposure might help to explain the much more severe symptoms in those workers that were likely to have been pre-exposed. If correct this assumption would confirm similar find- 
ings in earlier reports as reviewed by Alexeeff and Kilgore. ${ }^{5}$

None of our patients showed evidence of $\mathrm{CH}_{3} \mathrm{Br}$ related lung damage. Signs of systemic $\mathrm{CH}_{3} \mathrm{Br}$ poisoning may follow both inhalational and dermal exposure. ${ }^{618}$ Lung damage usually occurs after high level inhalational exposure. At lower levels of inhalational exposure, signs of systemic poisoning may develop in the absence of lung damage. ${ }^{27}$ Increased serum glutamic oxaloacetic transaminase and glutamic pyruvic transaminase activities were found only in the two serious cases. As these rapidly become normal while high dosed sodium thiopental treatment continued, they probably were the result of true $\mathrm{CH}_{3} \mathrm{Br}$ related hepatotoxicity and not induced by sodium thiopental. Although previous reports have noted the possible renal toxicity of $\mathrm{CH}_{3} \mathrm{Br}$, none of our patients showed any evidence of this.

Persisting fever $\left(>39^{\circ} \mathrm{C}\right.$ for more than three weeks), despite several courses of antimicrobial treatment and in the absence of infection proved by culture has to our knowledge not been reported before and its direct relation with $\mathrm{CH}_{3} \mathrm{Br}$ poisoning remains unclear. The fever did not have a pattern consistent with a possible central origin.

Symptoms of the central nervous system such as headache, nausea, vomiting, a sense of drunkenness, ataxia, slurred speech, and confusion are the more common and early manifestations of systemic $\mathrm{CH}_{3} \mathrm{Br}$ poisoning and may be preceded by a symptom free interval of two hours ${ }^{27}$ as was the case in our patients. Progression to the more severe stage with coma, generalised seizures, myoclonus, and a distal axonopathy may follow within hours to days. Treatment with diphenylhydantoin, diazepam, paraldehyde, or clonazepam is often not sufficient to suppress convulsive activity. In these cases it may be necessary to resort to anaesthesia (for example with thiopental). Convalescence may take months and not infrequently shows psychiatric disturbances, seizures, action myoclonus and ataxia as residual and sometimes permanent manifestations. ${ }^{19}$ The drug resistant status epilepticus, by some authors also described as status myoclonicus, is associated with a high mortality. ${ }^{71920}$ The myoclonus is usually assymmetrical, distally located, and may occur spontaneously or in response to somatosensory stimuli. Electroencephalograms in these patients showed polyspike and wave complexes with frontal predominance. Also giant somatosensory evoked potentials may be recorded. By using a back averaging technique, Uncini $e t$ al were able to show that the status myoclonicus, as seen in some cases of serious $\mathrm{CH}_{3} \mathrm{Br}$ poisoning, may represent a form of cortical reflex myoclonus. ${ }^{21}$

There is no established causal therapy for $\mathrm{CH}_{3} \mathrm{Br}$ poisoning. In the past haemoperfusion, chelating agents (for example, dimercaprol), and $\mathrm{N}$-acetylcysteine have been used. None of these drugs were used in the context of controlled prospective trials, however, and their reported effectiveness concerned only less severely poisoned patients. To date treatment can only be supportive and symptomatic. High dose thiopental anaesthesia seems effective in the treatment of $\mathrm{CH}_{3} \mathrm{Br}$ induced generalised seizures that have proved to be unresponsive to regular treatment with antiepileptic drugs.

Requests for reprints to: W N M Hustinx, Utrecht State University Hospital (AZU), Heidelberglaan 100, PO Box 85500, 3508GA Utrecht, The Netherlands.

1 Van den Oever R, Roosels D, Lahaye D. Actual hazard of methyl bromide fumigation in soil disinfection. $\mathrm{Br} J$ Ind Med 1982; 39:140-4.

2 Marraccini JV, Thomas GE, Ongley JP, Pfaffenberger CD, Davis JH, Bednarczyk LR. Death and injury caused by methyl bromide, an insecticide fumigant. J Forensic Sci 1983;3:601-7.

3 Behrens RH, Dukes DC. Fatal methyl bromide poisoning. Br J Ind Med 1986;43;561-2.

4 Dutch expert committee for occupational standards. Healthbased recommended occupational exposure limits for methyl bromide. Voorburg, The Netherlands: Directorate-General of Labour and the Ministry of Social Affairs and Employment, 1990.

5 Alexeeff BV, Kilgore WW. Methyl bromide. Residue reviews 1983;88:101-53.

6 Zwaveling JH, de Kort WLAM, Meulenbelt J, Hezemans-Boer $M$, Vloten WA van, Sangster B. Exposure of the skin to methyl bromide: a study of six cases occupationally exposed to high concentrations during fumigation. Human Toxicology 1987;6: 491-5.

7 Hine CH. Methyl bromide poisoning. J Occup Med 1969;11: $1-10$.

8 Herzstein J, Cullen MR. Methyl bromide intoxication in four field-workers during removal of soil fumigation sheets. Am J Ind Med 1990;17:321-6.

9 Sato M, Hasegawa H, Homma T, Miyagawa M, Suda $M$, Sudo A. Studies on intoxication due to methyl bromide (2)distribution of methyl bromide and bromine in the living body. Sangyo Igaku Sogo-Kenkyusho Nempo 1980a:22 (Cited in Pest Abstracts 1980;81:3225).

10 Honma T, Miyagawa M, Sato M, Hasegawa $\mathrm{H}$. Neurotoxicity of methyl bromide in rats. Toxicol Appl Pharmacol 1985;81: 183-91.

11 Sangster B, Blom JL, Sekhuis VM, Loeber JG et al. The influence of sodium bromide in man: a study in human volunteers with special emphasis on the endocrine and nervous system. Food Chem Toxicol 1983;21:409-19.

12 Soremark R. Distribution and kinetics of bromide ions in the mammalian body. Some experimental investigations using $\mathbf{B r}$ 80M and Br 82. Acta Radiol Suppl 1960;190:1.

13 Leeuwen FXR van, Sangster B. The toxicology of bromide ion. Critical Reviews in Toxicology 1987;18:189-213.

14 Verberk MM, Rooyakkers-Beemster $T$, Vlieger $M$ de, Vliet $A G M$ van. Bromine in blood, EEG and transaminases in methyl bromide workers. Br J Ind Med 1979;36:159-64.

15 Bradford JC. Methyl bromide and related compounds. In: Haddad LM and Winchester JF, eds. Clinical management of poisoning and drug overdose. 2nd ed. Philadelphia: W B Saunders Company, 1990.

16 Hessing JGM. Biologische monitoring van blootstelling aan methyl bromide bij grondontsmetters. MBL 1980-1, TNO, Medisch Biologisch Laboratorium.

17 Rathus EM, Landy PJ. Methyl bromide poisoning. Br J Ind Med 1961;18:53

18 Bruhin J. Perkutane Vergiftungen mit Methylbromid bei der Schaedlingsbekaempfung. Thesis Universitaet Züerich: Mettler and Saltz AG, Bern 1942.

19 Shield LK, Coleman TL, Markesbery WR. Methyl bromide intoxication: neurologic features, including simulation of Rey syndrome. Neurology 1977;27:959-62.

20 Mellerio F, Levy-Ancover MA. Myoclonies d'origine toxique. Rev EEG Neurophysiol Clin 1982;12:210-18.

21 Uncini A, Basciani M, DiMuzio A, Antonini D, Onofri M. Methyl bromide myoclonus: an electrophysiological study. Acta Neurol Scand 1990;81:159-64.

Accepted 27 April 1992 